\title{
Desenvolvimento da consciência fonológica: \\ uma proposta de trabalho com o gênero trava-lingua
}

Development of phonological awareness:

a proposal of activities with the genre tongue-twister

\author{
Luci Piletti Niedermayer ${ }^{1}$ \\ Universidade Estadual do Oeste do Paraná \\ Carmen Teresinha Baumgartner ${ }^{2}$ \\ Universidade Estadual do Oeste do Paraná \\ Clarice Cristina Corbari ${ }^{3}$ \\ Universidade Estadual do Oeste do Paraná \\ DOI: https://doi.org/10.5902/2176148534667
}

\begin{abstract}
Resumo: Este artigo apresenta algumas reflexões sobre o trabalho com gêneros textuais e o desenvolvimento da consciência fonológica no processo de aquisição da leitura e escrita, bem como descreve uma proposta de trabalho com o gênero trava-língua para alunos em fase de alfabetização. Trata-se de pesquisa-ação pautada na perspectiva da relação necessária entre alfabetização e letramento, em que se busca desenvolver as habilidades de leitura e escrita voltadas aos usos sociais da linguagem ao mesmo tempo em que promove a apropriação do sistema de escrita alfabética.
\end{abstract}

Palavras-chave: Alfabetização. Letramento. Consciência fonológica. Gênero trava-língua.

Abstract: This paper presents some reflections on the genre-based approach and the development of the phonological awareness in the process of acquisition of reading and writing, and describes a proposal of activities with the genre tongue-twister for students in process of reading and writing instruction. It is action research based on the perspective of the necessary relationship between the two dimensions of literacy, in which the aim is to develop the reading and writing skills considering the social uses of language while promoting the appropriation of the alphabetical writing system.

1 Mestranda do Programa de Pós-Graduação - Mestrado Profissional em Letras (ProfLetras) da Universidade Estadual do Oeste do Paraná (Unioeste). Docente da rede municipal de ensino de Santa Helena (PR).

2 Doutora em Letras. Docente do Programa de Pós-Graduação em Letras (PPGL) e do Mestrado Profissional em Letras (ProfLetras) da Universidade Estadual do Oeste do Paraná (Unioeste).

3 Doutora em Letras. Docente do Mestrado Profissional em Letras (ProfLetras) da Universidade Estadual do Oeste do Paraná (Unioeste). 
Keywords: Reading and writing instruction. Literacy. Phonological awareness. Genre tongue-twister.

Luci Piletti

Niedermayer

Carmen

Teresinha

Baumgartner

Clarice Cristina

Corbari

208

\section{Introdução}

Neste artigo, objetiva-se apresentar, com base em algumas reflexões concernentes ao desenvolvimento da consciência fonológica no processo de aquisição da leitura e escrita, uma proposta de trabalho com o gênero trava-língua para uma turma de alunos em fase de alfabetização. A proposta se pauta na perspectiva da relação necessária entre alfabetização e letramento, na qual o compromisso do professor alfabetizador deve ser o de desenvolver as habilidades de leitura e escrita voltadas aos usos sociais da linguagem, ao mesmo tempo em que promove a apropriação das convenções da escrita. Em outras palavras, trata-se da perspectiva de "alfabetizar letrando".

Em pesquisa realizada no banco digital de teses e dissertações da Coordenação de Aperfeiçoamento de Pessoal de Nível Superior (Capes), é possível encontrar alguns trabalhos sobre o papel da consciência fonológica no processo de alfabetização. Com relação às dissertações e teses defendidas a partir de 2010, citamos os trabalhos de Costa (2010), Espírito Santo (2013), Pereira (2014) e Mangueira (2016), que investigaram temas mais genéricos com relação ao desenvolvimento da consciência fonológica na aquisição da leitura e escrita. Mais relacionado ao tema que abordamos neste artigo, encontra-se o trabalho de Wolff (2015), no qual a autora investiga a rima em poemas infantis como evento linguístico desencadeador de ampliação da consciência linguística e como impulsionadora de estratégias de processamento da compreensão da linguagem, enfocando seu papel na aprendizagem da leitura e da escrita no período inicial de alfabetização. Destacamos que o componente lúdico das rimas, assim como dos trava-línguas, favorecem o desenvolvimento da consciência fonológica, considerando-se a perspectiva de aprender brincando.

Há também diversos artigos com referência à temática do desenvolvimento da consciência fonológica na alfabetização, em diversas áreas do conhecimento, mas poucos propõem ou descrevem atividades que possam ser aplicadas em sala de aula. Destaca-se, nesse sentido, o trabalho de Barrera e Maluf (2003), que aborda a influência da consciência fonológica, lexical e sintática sobre a aquisição da linguagem escrita, em que as pesquisadoras aplicaram duas tarefas de identificação de rimas e aliterações em uma sala de alunos em fase de alfabetização e con- 
cluíram que as crianças com melhor desempenho em leitura e escrita no final do ano foram aquelas que iniciaram o processo de alfabetização com níveis superiores no desenvolvimento da consciência metalinguística, sobretudo em seus aspectos fonológico e sintático.

Pode-se encontrar atividades que visam ao desenvolvimento da consciência fonológica em diversas páginas da Internet relativas à alfabetização, tais como Psicopedagogia em Ação (http://psicopedagogialudica.blogspot.com), Fonológica (http://www.fonologica.com.br), Nova Escola (https://novaescola.org.br), Educa Criança (https://educacrianca.com.br), Portal do Professor (http://portaldoprofessor.mec.gov.br) e Portal Educação (https://www.portaleducacao.com.br), entre outros sites. Porém, nem sempre as atividades estão vinculadas a um trabalho com gêneros textuais, como as que apresentamos neste artigo.

Desenvolvimento da consciência fonológica

Justifica-se, assim, a pertinência de nosso estudo, com vista a oferecer uma contribuição especialmente ao professor alfabetizador. Após breve reflexão teórica sobre questões relativas aos conceitos de alfabetização na perspectiva do letramento, ao trabalho com os gêneros textuais e ao papel da consciência fonológica na aquisição da linguagem escrita, descrevemos uma proposta de trabalho com o gênero textual trava-língua, cuja ludicidade incorpora-se ao universo infantil como importante elemento para o desenvolvimento da consciência fonológica, aspecto fundamental para a alfabetização. Destaca-se que a proposta foi aplicada em uma turma de alunos em fase de alfabetização ( $1^{\circ}$ ano do Ensino Fundamental) em uma escola municipal situada na cidade de Santa Helena, no Oeste do Paraná, de modo que, ao apresentá-la, faremos também algumas reflexões sobre os resultados verificados.

\section{A importância da alfabetização na perspectiva do letramento}

Embora muitas crianças já cheguem à escola sabendo ler e escrever, é essa instituição a principal responsável pelo desenvolvimento do domínio da linguagem oral e escrita em diferentes contextos de uso, em conformidade com a situação de interação, os propósitos comunicativos e os atores envolvidos na interlocução. Como a aprendizagem dos usos da língua implica a aquisição do sistema convencional da escrita, a escola assume a função de desenvolver, de forma concomitante, aspectos como a relação fonema-grafema, a norma ortográfica, o domínio gradativo da norma padrão, a compreensão textual, a produção de texto, o desenvolvimento da oralidade, entre outros. 
Essas duas dimensões da aquisição da leitura e escrita - isto é, a aquisição do sistema convencional da escrita e a aprendizagem dos usos Luci Piletti da língua - refletem-se nos conceitos de alfabetização e letramento: enNiedermayer quanto o primeiro conceito se refere à aquisição do sistema convencional de escrita, o segundo está ligado ao desenvolvimento de habilidades de Carmen uso desse sistema em atividades de leitura e escrita, nas práticas sociais Teresinha Baumgartner

Clarice Cristina Corbari que envolvem a língua escrita (TFOUNI, 1995; SOARES, 1999; 2003; 2004). Conforme Mendonça,

O conceito de letramento (e, por extensão, de sujeito letrado) surgiu para dar conta da complexidade de eventos que lidam com a escrita. Mais amplo que o conceito restrito de alfabetização, a noção de letramento inclui não só o domínio das convenções da escrita, mas também o impacto social que dele advém.

[...] Um dos princípios que norteiam a perspectiva do letramento é que a aquisição da escrita não se dá desvinculada das práticas sociais em que se inscreve: ninguém lê ou escreve no vazio, sem propósitos comunicativos, sem interlocutores, descolado de uma situação de interação; as pessoas escrevem, lêem e/ou interagem por meio da escrita, guiadas por propósitos interacionais, desejando alcançar algum objetivo, inseridas em situações de comunicação (MENDONÇA, 2007, p. 46-47).

No entanto, com o avanço das discussões sobre as noções de alfabetização, Soares (2004, p. 8-9) observa que, no Brasil, ocorreu o que ela chamou de "desinvenção da alfabetização", "certo apagamento da alfabetização" ou "progressiva perda da especificidade da alfabetização", por conta de equívocos teóricos e metodológicos. A autora refere-se às falhas resultantes da ausência do trabalho sistemático com o código alfabético e ortográfico em razão da "exclusividade atribuída a apenas uma das facetas da aprendizagem da língua" (SOARES, 2004, p. 9). A autora acredita que

[...] essa perda de especificidade da alfabetização é fator explicativo - evidentemente, não o único, mas talvez um dos mais relevantes - do atual fracasso na aprendizagem e, portanto, também no ensino da língua escrita nas escolas brasileiras, fracasso hoje tão reiterado e amplamente denunciado (SOARES, 2004, p. 9). 
Soares (2004) atribui esse abandono da especificidade da alfabetização a equívocos na adoção da concepção holística da aprendizagem da língua escrita, em que o sistema grafofônico (as relações fonema-grafema) deixou de ser objeto de ensino direto e explícito, já que sua aprendizagem decorreria naturalmente da interação com a língua escrita; ou seja, a aprendizagem do sistema de escrita alfabética passou a ser considerada um processo autônomo por parte do indivíduo. Segundo a autora, essa tendência foi amplamente adotada na perspectiva de fugir à "excessiva especificidade" da alfabetização dos métodos anteriores, mas, com isso, apagou-se a necessária especificidade do processo de alfabetização. A partir dessas constatações, a autora advoga a necessidade de um retorno consciente ao trabalho com os aspectos específicos da alfabetização, sem perder de vista a noção de letramento, também Desenvolvimento da consciência fonológica com sua especificidade.

Assim como outros autores, Albuquerque $(2007$, p. 18) alerta que “[...] apenas o convívio intenso com textos que circulam na sociedade não garante que os alunos se apropriem da escrita alfabética, uma vez que essa aprendizagem não é espontânea e requer que o aluno reflita sobre as características do nosso sistema de escrita" (ALBUQUERQUE, 2007, p. 18). Soares (1999), ao fazer a distinção entre alfabetizar e letrar - ações distintas, mas não inseparáveis -, afirma que o ideal seria alfabetizar letrando, isto é, ensinar a ler e escrever no contexto das práticas sociais da leitura e da escrita.

Concordamos, portanto, com Albuquerque (2007) quando afirma que

$$
\begin{aligned}
& \text { [...] a escola deve garantir, desde cedo, que as crianças se apro- } \\
& \text { priem do sistema de escrita alfabético, e essa apropriação não } \\
& \text { se dá, pelo menos para a maioria das pessoas, espontaneamente, } \\
& \text { valendo-se do contato com textos diversos. É preciso o desen- } \\
& \text { volvimento de um trabalho sistemático de reflexão sobre as ca- } \\
& \text { racterísticas do nosso sistema de escrita alfabético (ALBUQUER- } \\
& \text { QUE, 2007, p. 19). }
\end{aligned}
$$

É nesse sentido que sugerimos uma proposta de trabalho com a consciência fonológica a partir de um gênero textual que pertence ao universo da criança, conforme apresentaremos mais adiante. 


\section{Gêneros textuais e letramento}

A abordagem dos gêneros em sala de aula está intimamente ligada à Luci Piletti noção de letramento. Se o letramento se refere às práticas sociais de Niedermayer leitura e escrita, então, trata-se de um processo que ocorre quando o sujeito está envolvido em interações ou situações de uso dos gêneros Carmen orais e escritos que circulam na sociedade. No que se refere à leitura, Teresinha Baumgartner

Clarice Cristina Corbari

Em sociedade, são múltiplos e diversificados os usos da leitura. Lê-se para conhecer. Lê-se para ficar informado. Lê-se para aprimorar a sensibilidade estética. Lê-se para fantasiar e imaginar. Lê-se para resolver problemas. E lê-se também para criticar e, dessa forma, desenvolver posicionamento diante dos fatos $\mathrm{e}$ das idéias que circulam através dos textos (SILVA, 1998, p. 27).

Esses propósitos comunicativos citados como exemplos por Silva (1998) estão relacionados a práticas de letramento inevitavelmente mediadas por gêneros. Em sociedade, lemos, escrevemos, falamos/dizemos e ouvimos gêneros diversificados.

$\mathrm{Na}$ perspectiva do que afirma Bronckart (1999, p. 103), que entende que "a apropriação dos gêneros é um mecanismo fundamental de socialização, de inserção prática nas atividades comunicativas humanas", cabe à escola proporcionar aos alunos o contato com uma grande diversidade de gêneros orais e escritos, abrangendo várias esferas de circulação. De acordo com esse entendimento, Mendonça afirma:

Cada vez mais, o conceito de letramento é considerado central para a compreensão dos processos de ensino-aprendizagem e para a intervenção dos professores em sala de aula. Um dos princípios que norteiam a perspectiva do letramento é que a aquisição da escrita não se dá desvinculada das práticas sociais em que se inscreve: ninguém lê ou escreve no vazio, sem propósitos comunicativos, sem interlocutores, descolado de uma situação de interação; as pessoas escrevem, lêem e/ou interagem por meio da escrita, guiadas por propósitos interacionais, desejando alcançar algum objetivo, inseridas em situações de comunicação (MENDONÇA, 2007, p. 46-47) 
No contexto escolar, no entanto, há duas questões a serem consideradas na abordagem dos gêneros. A primeira é a necessidade de didatização dos gêneros, conforme aponta Mendonça:

\begin{abstract}
[...] é preciso realizar um processo de didatização para atingir os objetivos pedagógicos na abordagem dos gêneros. Esse processo de didatização é desencadeado pela necessidade de ensinar, que exige a modificação do conhecimento, convertendo-o em objeto de ensino: é preciso selecionar, adaptar e organizar conteúdos, além de elaborar estratégias e material didático pertinentes aos objetivos pedagógicos (MENDONÇA, 2007, p. 49).
\end{abstract}

A segunda questão a ser considerada, tratando-se especificamente do ensino nas séries iniciais, é a necessidade, já mencionada, de não só desenvolver as habilidades de leitura e escrita, mas também promover a apropriação de conhecimentos do sistema alfabético e das convenções da norma urbana de prestígio. Trata-se da proposta de alfabetizar letrando, cujo princípio básico é o de que a apropriação do sistema convencional de escrita e a inserção nas práticas sociais de leitura e escrita se dariam de forma simultânea e complementar. É nessa perspectiva que propomos, mais adiante, um conjunto de atividades com o gênero trava-língua com o intuito de desenvolver a consciência fonológica do aluno em processo de alfabetização.

\section{O desenvolvimento da consciência fonológica na aquisição da linguagem escrita}

Um aspecto fundamental para a aprendizagem da escrita é o desenvolvimento da consciência fonológica, que está intimamente relacionado à apropriação do sistema convencional de escrita. Piccoli e Camini (2012, p. 103) definem consciência fonológica como "[...] um conjunto de habilidades que permite à criança compreender e manipular unidades sonoras da língua, conseguindo segmentar unidades maiores em menores". Cunha e Capellini, por sua vez, apresentam uma definição mais detalhada:
Desenvolvimento da consciência fonológica

\footnotetext{
A consciência fonológica é uma parte integrante da consciência metalinguística e está relacionada à habilidade de refletir e manipular os segmentos da fala, abrangendo, além da capacidade de reflexão (consultar e comparar), a capacidade de operar com rimas,
} 
aliteração, sílabas e fonemas (contar, segmentar, unir, adicionar, suprimir, substituir e transpor) (CUNHA; CAPELLINI, 2011, p. 87).

Luci Piletti

Niedermayer

Carmen

Teresinha

Baumgartner

Clarice Cristina

Corbari

214

Desenvolver a consciência fonológica do aluno implica exercitar habilidades que incluem desde a simples percepção global do tamanho da palavra e de semelhanças fonológicas entre as palavras até a segmentação e manipulação de sílabas e fonemas (LOPES, 2004). Por essa razão, há necessidade de um trabalho sistematizado com essas habilidades durante o período da alfabetização, uma vez que, conforme Piccoli e Camini (2012, p. 103), “[...] da consciência fonológica depende uma série de processos fundamentais para a aprendizagem da leitura e da escrita". Sobre isso, Bortoni-Ricardo (2006) afirma:

\footnotetext{
Pesquisadores da área de alfabetização, em muitos países de escrita alfabética, argumentam, enfaticamente, que o reconhecimento das palavras desempenha um papel central no desenvolvimento da habilidade de leitura. Aprender a reconhecer palavras é a principal tarefa do leitor principiante, e esse reconhecimento é mediado pela fonologia. Por meio da decodificação fonológica, o aprendiz traduz sons em letras, quando lê, e faz o inverso, quando escreve (BORTONI-RICARDO, 2006, p. 204).
}

Morais (1995) ressalta que, enquanto a consciência de segmentos suprafonêmicos desenvolve-se espontaneamente, em virtude do fato de que sílabas isoladas são manifestadas como unidades discretas da fala, o desenvolvimento da consciência fonêmica necessita da introdução formal a um sistema de escrita alfabético. Godoy (2001) também considera a consciência fonológica um fator crítico e decisivo na constituição de leitores capazes, já que se trata de um aspecto que exerce significativa influência no processo de aquisição da leitura e escrita nos anos iniciais.

Segundo Piccoli e Camini (2012), as habilidades relacionadas à consciência fonológica podem ser agrupadas em três níveis: consciência silábica, consciência de rimas e aliterações e consciência fonêmica. Conforme apontam Capellini e Ciasca (2000), a consciência linguística não emerge repentinamente, mas se desenvolve em um contínuo de etapas evolutivas sucessivas, não necessariamente lineares; resulta do desenvolvimento e do amadurecimento biológico em constantes trocas com o meio ou contexto, e é favorecida pelas complexas tarefas linguísticas a que se é submetido. 
As contribuições dos autores aqui brevemente citadas fornecem razões para defendermos a necessidade de instrução explícita sobre a estrutura da escrita alfabética para desenvolver a consciência de fonemas, com vista a contribuir para o sucesso no desenvolvimento das habilidades de leitura e escrita.

O Currículo Básico para a Escola Pública Municipal: Educação Infantil e Ensino Fundamental (Anos Iniciais) (AMOP, 2014), documento que orienta o ensino das séries iniciais no contexto escolar em que atuamos - região Oeste do Paraná -, destaca a importância do trabalho com o reconhecimento das rimas e as manipulações silábicas e fonêmicas como habilidades a serem desenvolvidas com os alunos. O objetivo é que o aluno compreenda a relação entre fonema e grafema, a fim de que se efetive a aquisição do sistema de escrita alfabética. $O$ documento ainda destaca

Desenvolvimento da consciência fonológica

\section{O uso de trava-línguas no desenvolvimento da consciência fonológica}

Os trava-línguas são frases difíceis de pronunciar, formadas por uma sucessão de palavras caracterizadas por unidades sonoras de difícil articulação, repetição de fonemas e trocas vocálicas e consonantais. Conforme a definição de Nascimento (2005, p. 55), “a rápida sucessão de palavras ordenadas pela repetição dos mesmos fonemas ou de fonemas vizinhos constitui o trava-língua". Trata-se, efetivamente, de um jogo verbal cujo objetivo é repetir as frases de forma rápida, com pronúncia clara e sem erros de articulação; não obstante, a troca ou omissão de sílabas ou erro em sua articulação é frequente, o que produz um resultado que faz rir.

Nascimento (2005) lembra que o trava-língua faz parte do universo folclórico, constituindo um gênero oral sem definição de autoria. São exemplos de trava-línguas de origem popular: (a) "Num ninho de mafagafos, cinco mafagafinhos há. Quem os desmafagafizar, bom desmafagafizador será"; (b) "O doce perguntou para o doce qual era o doce mais doce que o doce da batata-doce. 0 doce respondeu pro doce que o doce mais doce é o doce de batata-doce".

Na poesia infantil, esse gênero ocupa papel de desafio lúdico para as crianças que se encontram em fase de desenvolvimento da linguagem verbal. Embora a maior parte dos trava-línguas priorizem o trabalho ar- 
ticulatório, utilizando o significante em detrimento do significado e frequentemente produzindo conjuntos com total ilogicidade, eles fazem Luci Piletti parte do universo infantil e da aprendizagem própria dessa fase da vida. Niedermayer Concordamos com Macedo, Pety e Passos (2005), para quem apenas o lúdico faz sentido à criança, razão pela qual a inserção da dimensão lúCarmen dica nos projetos pedagógicos constitui uma forma de tornar o aprendiTeresinha zado significativo, por estar alinhada à perspectiva de compreensão do Baumgartner

Clarice Cristina Corbari mundo inerente à faixa etária dos alunos em processo de alfabetização. Dadas as características apontadas, os trava-línguas constituem um ótimo exercício de consciência fonológica, haja vista que esse gênero oral proporciona a reflexão sobre a utilização de elementos linguísticos que vão sendo, no decorrer do processo de alfabetização, (re)conhecidos por meio do exercício de escrita.

\section{Metodologia}

Para a efetivação do objetivo proposto, primeiramente, procedemos a uma pesquisa bibliográfica para fundamentação teórica do trabalho, conforme apresentamos nas seções anteriores. Com base nesses pressupostos teóricos, elaboramos atividades com gêneros textuais diversos, que foram aplicadas durante o mês de junho de 2018, em uma turma de $1^{\circ}$ ano do Ensino Fundamental, composta por 14 alunos, com idades entre 5 e 7 anos, em uma escola municipal situada na cidade de Santa Helena, no Oeste do Paraná. Desse material elaborado, selecionamos um recorte, que é o referente ao trabalho com trava-línguas.

A elaboração e aplicação da proposta se inserem na metodologia da pesquisa-ação, que demanda a participação direta do pesquisador na problemática investigada, partindo do embasamento teórico para refletir sobre a prática e buscar solução para seus problemas em sala de aula. Segundo Engel,

No ensino, a pesquisa-ação tem por objeto de pesquisa as ações humanas em situações que são percebidas pelo professor como sendo inaceitáveis sob certos aspectos, que são suscetíveis de mudança e que, portanto, exigem uma resposta prática. [...] A pesquisa-ação é situacional: procura diagnosticar um problema específico numa situação também específica, com o fim de atingir uma relevância prática dos resultados (ENGEL, 2000, p. 184). 
Ao partirmos do trabalho com um gênero textual que circula socialmente, engajamo-nos na perspectiva de alfabetizar letrando. No entanto, é necessário que o gênero passe por um processo de didatização para atingir objetivos pedagógicos; ou seja, é preciso transformá-lo em objeto de ensino (MENDONÇA, 2007).É nesse sentido que elaboramos as atividades, buscando, a partir de uma pesquisa sobre o tema, inserir o gênero trava-línguas e realizar atividades típicas de alfabetização, tais como repetir sons/fonemas, manipular palavras, relacionar imagem e grafia, pintar letras, entre outras estratégias, conforme pode ser visto na próxima seção.

As impressões derivadas da aplicação da atividade foram registradas em diário de campo, que constitui importante instrumento para anotar informações, observações e reflexões pertinentes à ação que está sendo desenvolvida.

$\mathrm{Na}$ próxima seção, apresentamos as atividades desenvolvidas e

Desenvolvimento da consciência fonológica tecemos algumas reflexões sobre os resultados de sua aplicação.

\section{Proposta de intervenção pedagógica: descrição e resultados}

Para desenvolver a proposta em sala de aula, partimos do encaminhamento, aos alunos, de uma pesquisa inicial acerca do gênero trava-língua, conforme o quadro a seguir (Figura 1), com o intuito de contextualizar o gênero entre os alunos e seus familiares.

TRAVA-LÍNGUAS

Os trava-línguas são textos que trabalham com unidades sonoras de difícil articulação e com a repetição de fonemas. Servem para fazer exercícios e jogos de linguagem, enfim, constituem uma brincadeira com as palavras.

EX: O RATO ROEU A ROUPA DO REI DE ROMA.

TAREFA:

Pesquise com seus familiares quais trava-línguas eles conhecem. Peça para alguém escrever para você trazer à escola e socializar com os colegas.

Figura 1 - Recorte do material trabalhado com os alunos - Parte 1: tarefa pré-aula

$\mathrm{Na}$ data da apresentação da pesquisa, destinamos um tempo para que cada aluno relatasse como ocorreu a atividade extraclasse e quem escreveu o trava-língua; se os familiares lembraram de alguns exemplos ou tiveram de pesquisar na Internet; se gostaram de brincar usando os trava-línguas conhecidos; e se sabiam para que serviam. Ressaltamos que todos os alunos realizaram a tarefa. Em alguns casos, os familiares escreveram 
Luci Piletti

Niedermayer

Carmen

Teresinha

Baumgartner

Clarice Cristina

Corbari

218

um ou dois trava-línguas conhecidos, ao passo que outros fizeram pesquisa na Internet e registraram uma quantidade maior de trava-línguas. Isso resultou em uma grande diversidade de textos coletados na tarefa.

Podemos avaliar que essa atividade foi muito produtiva, pois proporcionou reconhecimento do gênero trava-língua por parte dos familiares dos alunos, que pesquisaram exemplos de trava-línguas e as leram junto às crianças. No momento da exposição oral, alguns alunos se lembraram dos trava-línguas escritos pelos familiares; outros apenas se lembraram dos trava-línguas no momento em que a professora fazia a leitura. Destacamos, a título de exemplificação, alguns trava-línguas registrados na tarefa dos alunos: "A aranha arranha o jarro, o jarro arranha a aranha"; "O tatu tá? Se o tatu não tá e a mulher do tatu tá é a mesma coisa que o tatu tá"; "Olha o sapo dentro do saco, o saco com o sapo dentro, o sapo batendo papo, e o papo soltando vento", "Farofa feita com muita farinha fofa faz uma fofoca feia".

Na sequência da aula, selecionamos os trava-línguas de que os alunos mais gostaram, os quais foram recitados coletivamente, com base na ideia de que o processo de alfabetização nos anos iniciais requer que a consciência fonológica seja trabalhada de forma lúdica para favorecer o desenvolvimento das habilidades de percepção e manipulação da estrutura sonora das palavras. Concomitantemente, promovemos a identificação dos sons/fonemas mais repetidos em cada texto e questionamos oralmente sobre a representação gráfica de cada fonema, que foi em seguida registrada no quadro de giz.

$\mathrm{Na}$ aula seguinte, organizamos um mural com os textos levados pelos alunos, a fim de que estes tivessem acesso diário aos trava-línguas pesquisados em casa. Essa exposição favoreceu, em diversos momentos, a leitura e/ou pseudoleitura ${ }^{4}$ do gênero em estudo.

Para que os alunos conhecessem mais profundamente a estrutura desse gênero, selecionamos o seguinte trava-língua para discussão.
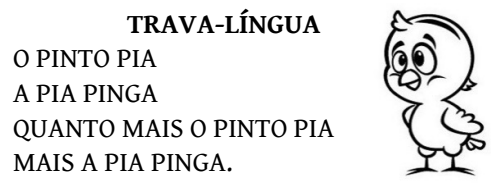

Figura 2 - Recorte do material trabalhado com os alunos - Parte 2: exploração de trava-língua

4 Trata-se de "leitura" baseada em predições sobre o conteúdo, em que os alunos "leem" sem saber efetivamente o que está escrito a partir de observação das imagens ou, no caso em tela, a partir da memorização prévia dos trava-línguas. 
A discussão oral sobre o trava-língua selecionado foi baseada nas seguintes questões:

- Podemos saber quando, em que contexto e por quem foi criado este trava-língua? Por quê?

- É possível compreender o sentido deste texto?

- Para quem este trava-língua foi criado?

- Onde se pode encontrar este gênero escrito?

- Quem lê trava-línguas?

- Você acha interessante aprender os trava-línguas e pronunciá-los? Por quê?

Desenvolvimento da consciência fonológica

Após o momento de oralização, os alunos realizaram as atividades do quadro a seguir.

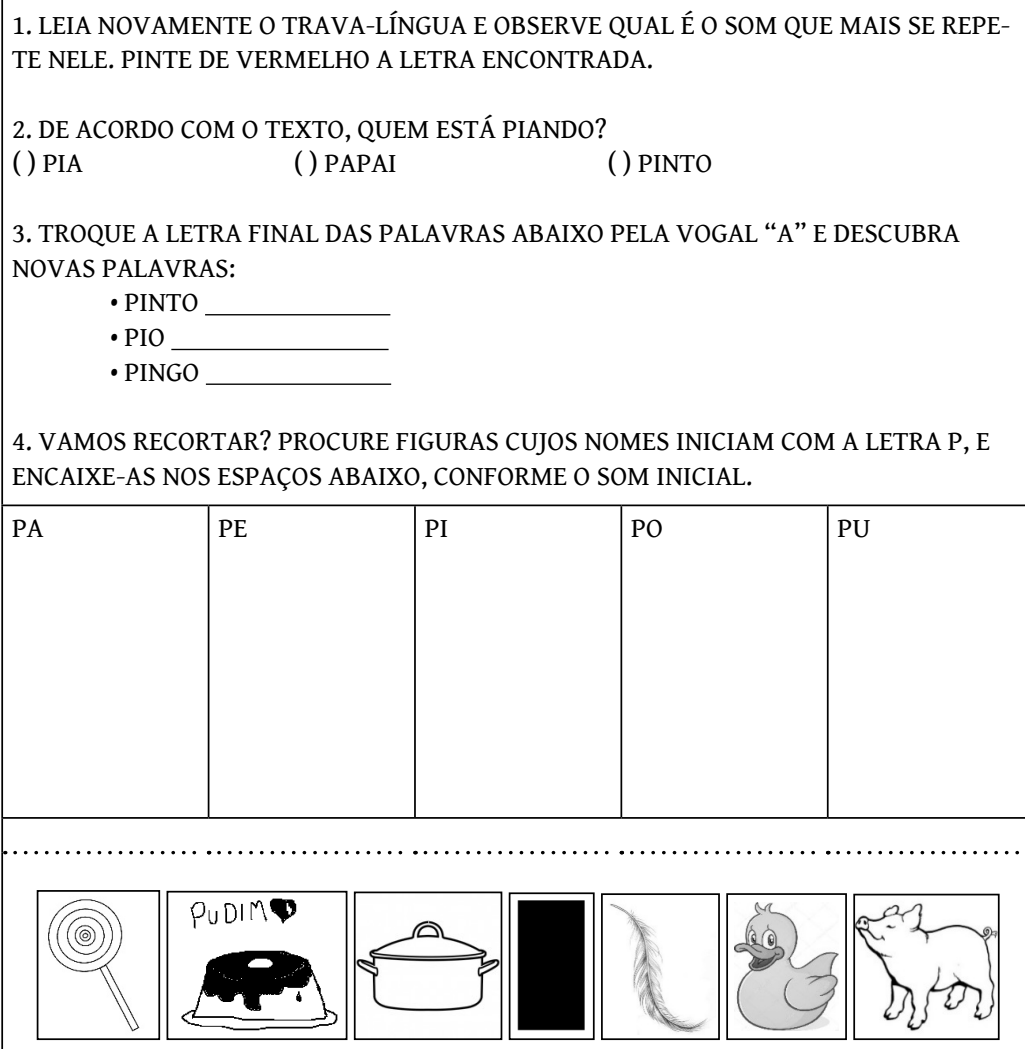

Figura 3 - Recorte do material trabalhado com os alunos - Parte 3: exercícios de desenvolvimento da consciência fonológica 
Com essas atividades, enfatizamos a letra (grafema) P e o correspondente fonema $/ \mathrm{p} /$, de forma que os alunos identificassem o formato Luci Piletti gráfico da letra, assim como o som representado por ela, que é uma Niedermayer consoante surda bilabial.

Durante a atividade 4, alguns alunos precisaram de auxílio com Carmen relação à identificação da sílaba inicial, uma vez que ainda não domiTeresinha nam a leitura silábica. Ressalta-se que essa atividade serviu de reflexão Baumgartner

Clarice Cristina fonológica, por conta da observância do som inicial de cada figura. Em razão disso, após o recorte e a colagem das figuras, foi proposta a escriCorbari ta, no caderno, das palavras mencionadas e marcação da sílaba inicial de cada uma com lápis de cor.

$\mathrm{Na}$ aula seguinte, as atividades basearam-se em outro trava-língua, envolvendo o $\mathrm{R}$ em início de palavra.

1. PINTE DE AZUL A LETRA QUE MAIS SE REPETE NO TRAVA-LÍNGUA ABAIXO:

O RATO ROEU A ROUPA DO REI DE ROMA.

2. LIGUE CADA PALAVRA À FIGURA CORRESPONDENTE:

REI

RATO

CARRO

BARATA
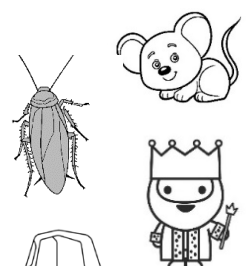

3. NESTA SALA, QUE NOMES DE ALUNOS SÃO ESCRITOS COM A LETRA R? VAMOS FAZER UMA LISTA E LER.

4. COMPLETE AS PALAVRAS CRUZADAS:

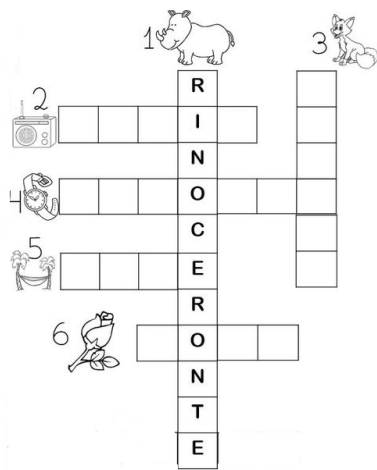

Figura 4 - Recorte do material trabalhado com os alunos - Parte 4: exercícios de reforço sobre a pronúncia do $\mathrm{R}$ 
Com esse trava-língua, além de enfatizar a pronúncia do R em posição inicial de palavra, refletimos com os alunos sobre os diferentes sons desse grafema, de acordo com sua localização nas palavras. Conforme defendem Cunha e Capellini (2011), atividades como essa, ao permitirem exercitar a capacidade de operar com rimas, aliteração, sílabas e fonemas, desenvolvem a habilidade de refletir sobre os segmentos da fala e manipulá-los.

Apresentamos aos alunos, na sequência da aula, o jogo Trinca Mági$\mathrm{ca}^{5}$, cujos objetivos didáticos são: compreender que as palavras são compostas por unidades sonoras; perceber que palavras diferentes podem possuir, em seu final, partes sonoras iguais (as rimas); desenvolver a consciência fonológica, por meio da exploração de rimas; e comparar palavras quanto às semelhanças sonoras. Conforme o aluno falava o nome de sua figura, $a$ professora regente ${ }^{6}$ escrevia a palavra citada no quadro, e os alunos que

Desenvolvimento da consciência fonológica estavam com as outras duas figuras que formavam a trinca se manifestavam, apresentando suas figuras, cujos nomes eram também transcritos no quadro. Quando todas as trincas estavam registradas no quadro, cada aluno fez o registro e o desenho de um grupo de palavras, ou seja, do grupo de que fazia parte sua carta, como exemplifica a figura a seguir.

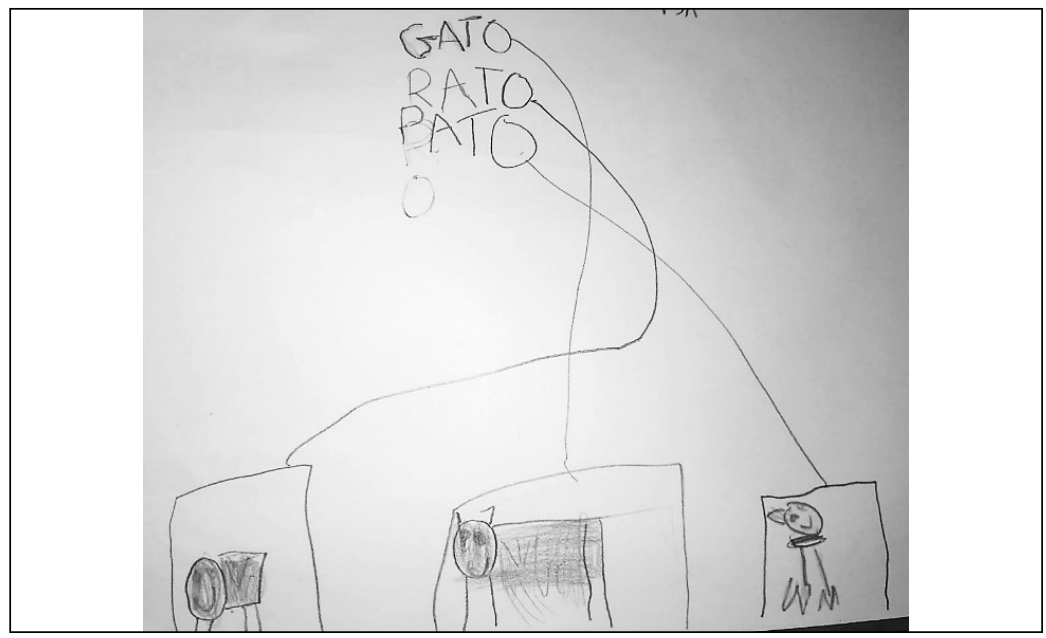

Figura 5 - Exemplo de atividade desenvolvida pelos alunos posteriormente à realização do jogo Trinca Mágica

5 Trata-se de um jogo constante da caixa de jogos do Pacto Nacional pela Alfabetização na Idade Certa (PNAIC), composto por 24 cartas contendo uma figura cada, que formam oito trincas de figuras cujos nomes rimam entre si (por exemplo, cola/mola/bola). As regras do jogo estão disponíveis em: $<$ http://pnaicparanagua.blogspot.com/2013/07/4-jogos-na-alfabetizacao-trinca-magica.html>.

6 Destaca-se que a professora regente é uma das autoras deste artigo. 
Ao final dessa atividade, cada aluno mostrou aos colegas seus registros e verbalizou as três palavras de sua carta. Esse jogo permitiu que os

Luci Piletti

Niedermayer

Carmen

Teresinha

Baumgartner

Clarice Cristina

Corbari

222 alunos refletissem sobre rimas e observassem a composição das palavras registradas, condição que favorece significativamente o desenvolvimento da consciência fonológica. Nesse sentido, Wolff (2015) esclarece que

A consciência fonológica [...] não é um elemento isolado e executado de forma mecânica em suas propriedades. Ela pode ser pesquisada e avaliada de forma mais objetiva e pontual, mas a atenção aos aspectos fonológicos se justifica pela distinção de diferentes sentidos daquilo que é dito em um enunciado, estando assim associados aos demais níveis de consciência linguística. A partir do enunciado gera-se um sentido específico que faz a atenção voltar-se à palavra e a seus segmentos, permitindo compreender sua estrutura sonora particular e identificar semelhanças e diferenças com relação a outras palavras (WOLFF, 2015, p. 39-40).

No momento seguinte, exploramos a consciência silábica com um exercício de percepção das partes constituintes das palavras por meio de batida de palmas. Inicialmente, o exercício foi realizado oralmente, no grande grupo, com a utilização de diversas palavras, e depois, cada aluno realizou sua atividade individualmente, conforme atividade ilustrada a seguir.

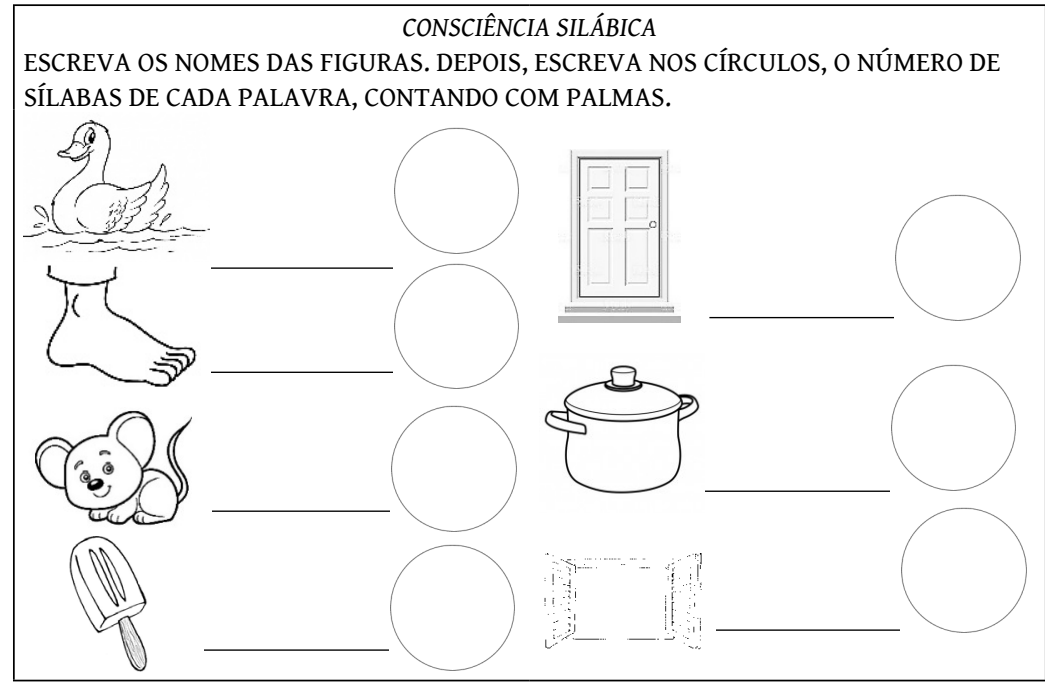

Figura 6 - Recorte do material trabalhado com os alunos - Parte 5: exercícios de consciência silábica 
Cabe aqui ressaltar a importância da realização do exercício de percepção dos fonemas por meio das palmas. Esse tipo de exercício rítmico e reflexivo deve ser realizado constantemente em classe de alfabetização, para que a criança compreenda, fale e ouça os sons que produz, com vistas a desenvolver a consciência fonológica.

Para finalizar o trabalho com o gênero escolhido, fizemos o ditado do trava-língua "O rato roeu a roupa do rei de Roma", com o propósito de verificar, nas tentativas de escrita, os avanços obtidos pelos alunos nas atividades de desenvolvimento da consciência fonológica. Reproduzimos, nas imagens a seguir, algumas dessas tentativas.

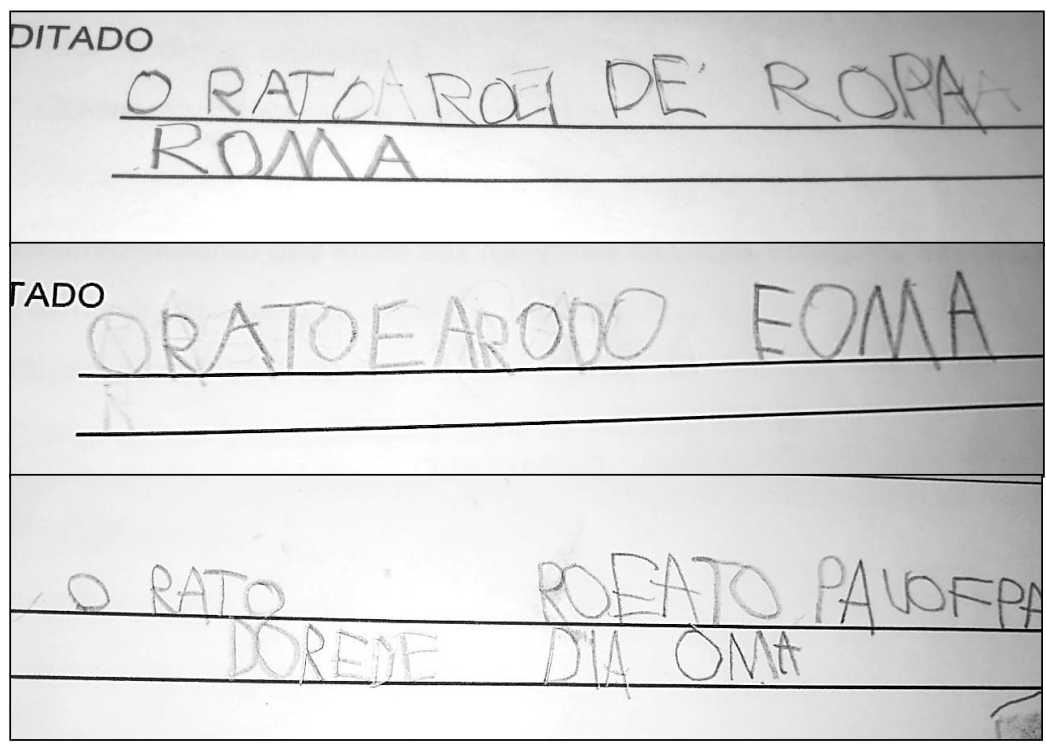

Figura 7 - Exemplos de atividade desenvolvida pelos alunos: ditado de trava-língua

Essa atividade permitiu constatar os avanços da turma no processo de aprendizagem a partir da intervenção realizada. As tentativas de escrita nos mostram o desenvolvimento de cada aluno e apontam quais aspectos linguísticos precisam ser enfatizados subsequentemente.

Além das atividades previamente organizadas, constantes da proposta de aplicação, sentimos, durante o percurso da aplicação, a necessidade de ampliar o trabalho, considerando o desenvolvimento da turma em geral e aspectos individuais dos alunos, pois constatamos dificuldades de compreensão de alguns alunos. Dessa forma, elaboramos mais algumas atividades de escrita no caderno, algumas tarefas de casa (por exemplo, pesquisa com recorte e colagem de 
figuras cujos nomes continham a letra $\mathrm{R}$, exercício de traçado das letras P e R, completar palavras com sílabas iniciais, entre outras) e Luci Piletti orientações individualizadas.

Niedermayer Em relação à pronúncia dos róticos, uma peculiaridade pode ser observada na turma, haja vista que alguns alunos não diferenciam, na fala, Carmen palavras com $\mathrm{R}$ no início de palavra em com $\mathrm{R}$ e RR no interior da palavra.

Teresinha Temos um grafema (R) com diversas realizações sonoras (como em rato, Baumgartner barata e carro), as quais são afetadas por variações dialetais, tema no qual não nos aprofundaremos aqui. Por essa razão, complementamos as ativi-

Clarice Cristina dades com a exploração de outros trava-línguas e até de cantigas em que Corbari ocorressem palavras cuja pronúncia evidenciava as diferentes realizações fonêmicas do R, o que acarretou em mudança na pronúncia dos alunos, principalmente quanto ao uso do $\mathrm{R}$ inicial. Ressaltamos que, nesse exercício de pronúncia, tomamos cuidado para evitar constrangimentos do aluno com relação à variedade dialetal que utiliza - que é legítima - ou mesmo com relação à timidez por receio de errar na realização da pronúncia.

\section{Considerações finais}

Ao concluirmos o trabalho apresentado neste artigo, podemos destacar alguns aspectos relevantes acerca da aquisição do sistema convencional de escrita do português. Como se trata de alunos em processo de alfabetização, a proposição de trabalho de reflexão linguística a partir de um texto do universo lúdico da criança imprime significado ao processo, se compararmos a um trabalho descontextualizado, em que se privilegia apenas o código linguístico, de forma mecânica.

Enfatizamos que o desenvolvimento da consciência fonológica consiste em um processo contínuo e planejado, com dinâmicas que envolvam o reconhecimento e a apropriação da relação grafema-fonema do português brasileiro, e deve ocorrer no interior de um conjunto de atividades diversificadas de linguagem, na perspectiva de alfabetizar letrando.

Os encaminhamentos metodológicos, no processo de alfabetização, precisam ser bem planejados, buscando superar as lacunas verificadas por muitos pesquisadores e perceptíveis a partir das avaliações externas. Porém, mais que os resultados de avaliação externa em si, o que se quer é um leitor e escritor bem-sucedido nas práticas sociais de leitura e escrita.

Sabemos que o trabalho do professor está tangenciado por muitas adversidades - precárias condições estruturais de muitas escolas, falta de acesso das famílias dos alunos a livros e outros materiais de 
leitura, problemas psicossociais dos alunos, ausência ou sucateamento de recursos tecnológicos que poderiam proporcionar dinâmicas diferenciadas para as aulas, desvalorização do professor pela sociedade, entre outros aspectos -, as quais dificultam a obtenção dos objetivos pretendidos. Entretanto, ainda que em meio a tantas dificuldades, uma ação docente organizada a partir de fundamentos teóricos e metodológicos consistentes é capaz de promover as habilidades necessárias para que o educando tenha acesso aos bens culturais e possa superar suas condições adversas, por meio do conhecimento.

Desenvolvimento da consciência fonológica

\section{REFERÊNCIAS}

ALBUQUERQUE, E. B. C. Conceituando alfabetização e letramento. In: SANTOS, C. F.; MENDONÇA, M. (Orgs.). Alfabetização e letramento: conceitos e relações. Belo Horizonte: Autêntica, 2007. p. 11-21.

AMOP - ASSOCIAÇÃO DOS MUNICÍPIOS DO OESTE DO PARANÁ. Currículo Básico para a Escola Pública Municipal: Educação Infantil e Ensino Fundamental (Anos Iniciais). Cascavel: Assoeste, 2014.

BARRERA, S. D.; MALUF, M. R. Consciência metalingüística e alfabetização: um estudo com crianças da primeira série do Ensino Fundamental. Psicologia: Reflexão e Crítica, Porto Alegre, 2003, v. 16, n. 3, p. 491-502. Disponível em: <http://www.scielo.br/scielo.php?pid=S0102$-79722003000300008 \& s c r i p t=s c i \_a b s t r a c t \& t l n g=p t>$. Acesso em: 19 dez. 2018.

BORTONI-RICARDO, S. M. Métodos de alfabetização e consciência fonológica: o tratamento de regras de variação e mudança. Scripta, Belo Horizonte, v. 9, n. 18, p. 201-220, 2006.

BRONCKART, J. P. Atividade de linguagem, textos e discursos: por um interacionismo sócio-discursivo. São Paulo: Educ, 1999.

CAPELLINI, S. A.; CIASCA, S. M. Avaliação da consciência fonológica em crianças com distúrbio específico da leitura e escrita e distúrbio de aprendizagem. Temas sobre Desenvolvimento, São Paulo, n. 8, p. 17-23, 2000. 
COSTA, D. C. A. Relação entre consciência fonológica e leitura/escrita de palavras isoladas. 2010. Dissertação (Mestrado em Fonoaudiologia)

Luci Piletti - Universidade Veiga de Almeida, Rio de Janeiro, 2010.

Niedermayer

CUNHA, V. L. O.; CAPELLINI, S. A. Habilidades metalinguísticas no

Carmen processo de alfabetização de escolares com transtornos de apren-

Teresinha dizagem. Psicopedagogia, São Paulo, v. 28, n. 85, p. 85-96, 2011.

Baumgartner

Clarice Cristina

ENGEL, G. I. Pesquisa-ação. Educar em Revista, Curitiba, n. 16, p. 181-191, dez. Corbari $\quad-40602000000200013 \& l n g=e n \& n r m=i s o>$. Acesso em: $18 \mathrm{dez} .2018$.

ESPÍRITO SANTO, E. R. Consciência fonológica e prática alfabetizadora: por uma ação teórico-metodológica para o ensino da linguagem escrita. 2013. Dissertação (Mestrado em Educação) - Universidade Estadual de Feira de Santana, Feira de Santana, 2013.

GODOY, D. M. A. Testes de consciência fonológica e suas relações com a aprendizagem da leitura no português. Dissertação (Mestrado em Linguística) - Universidade Federal de Santa Catarina, 2001.

LOPES, F. O desenvolvimento da consciência fonológica e sua importância para o processo de alfabetização. Psicologia Escolar e Educacional, São Paulo, v. 8, n. 2, p. 241-243, 2004.

MACEDO, L.; PETTY, A. L. S.; PASSOS, N. C. Os jogos e o lúdico na aprendizagem escolar. Porto Alegre: Artmed, 2005.

MANGUEIRA, M. C. B. R. A consciência fonológica e seu potencial preditivo de aquisição e aprendizado da leitura e da escrita. 2016. Dissertação (Mestrado em Linguística) - Universidade Estadual do Sudoeste da Bahia, Vitória da Conquista, 2016.

MENDONÇA, M. Gêneros: por onde anda o letramento? In: SANTOS, C. F.; MENDONÇA, M. (Orgs.). Alfabetização e letramento: conceitos e relações. Belo Horizonte: Autêntica, 2007. p. 37-56.

MORAIS, J. A arte de ler. São Paulo: Unesp, 1995. 
NASCIMENTO, E. L. Gêneros lúdicos no processo de letramento. Ponta Grossa: UEPG / Cefortec, 2005.

PEREIRA, E. S. Uma prática de mediação entre os saberes da oralidade e da escrita: despertando a consciência fonológica e a compreensão do processo de transição. 2014. Dissertação (Mestrado em Linguística e Ensino) - Universidade Federal da Paraíba, João Pessoa, 2014.

PICCOLI, L.; CAMINI, P. Práticas pedagógicas em alfabetização: espaço, tempo e corporeidade. São Paulo: Edelbra, 2012.

Desenvolvimento da consciência fonológica

SILVA, E. T. Criticidade e leitura: ensaios. Campinas: Mercado de Letras, 1998.

SOARES, M. Letramento: um tema em três gêneros. São Paulo: Autêntica, 1999.

Alfabetização: a ressignificação do conceito. Alfabetização $e$ Cidadania: Revista de Educação de Jovens e Adultos, Brasília, n. 16, p. 9-17, jul. 2003.

. Letramento e alfabetização: as muitas facetas. Revista Brasileira de Educação, Rio de Janeiro, n. 25, p. 1-13, 2004. Disponível em: <http:// www.scielo.br/pdf/rbedu/n25/n25a01.pdf>. Acesso em: 24 jul. 2007.

TFOUNI, L. V. Letramento e alfabetização. São Paulo: Cortez, 1995.

WOLFF, C. L. Descobrindo as rimas em poemas: estudo sobre os efeitos das rimas na consciência fonológica e suas relações com os demais níveis de consciência linguística durante o processo de alfabetização. 2015. Tese (Doutorado em Letras) - Pontifícia Universidade Católica do Rio Grande do Sul, Porto Alegre, 2015. 
